\title{
Activity Comparison of Epigenetic Modulators against the Hemoprotozoan Parasites Babesia divergens and Plasmodium falciparum
}

Leen N. Vanheer ${ }^{1}$, Björn F.C. Kafsack ${ }^{1, *}$

1 Department of Microbiology \& Immunology, Weill Cornell Medicine, New York, New York 10065, United States

*Email: bkafsack@med.cornell.edu

Supporting Information 


\section{Table of Contents}

Figure S1, Percent inhibition of all 324 compounds against $B$. divergens at 10 and $1 \mu \mathrm{M}$

Figure S2, Structural feature similarity landscape.................................... 2

Figure S3, Activity cliff analysis for Babesia divergens at $1 \mu \mathrm{M} \ldots \ldots \ldots \ldots \ldots \ldots . . . . .3$

Figure S4, Structural representation of the remaining activity cliff pairs in Figure $4 \mathrm{~A}$

Figure S5, Activity of diaminoquinazoline KMT inhibitors against $P$. falciparum .................................................................................... 5

Table S1, EC50 activity of epigenetic inhibitors tested grouped by target category 6

Table S2, EC90 activity of epigenetic inhibitors tested grouped by target category 6 


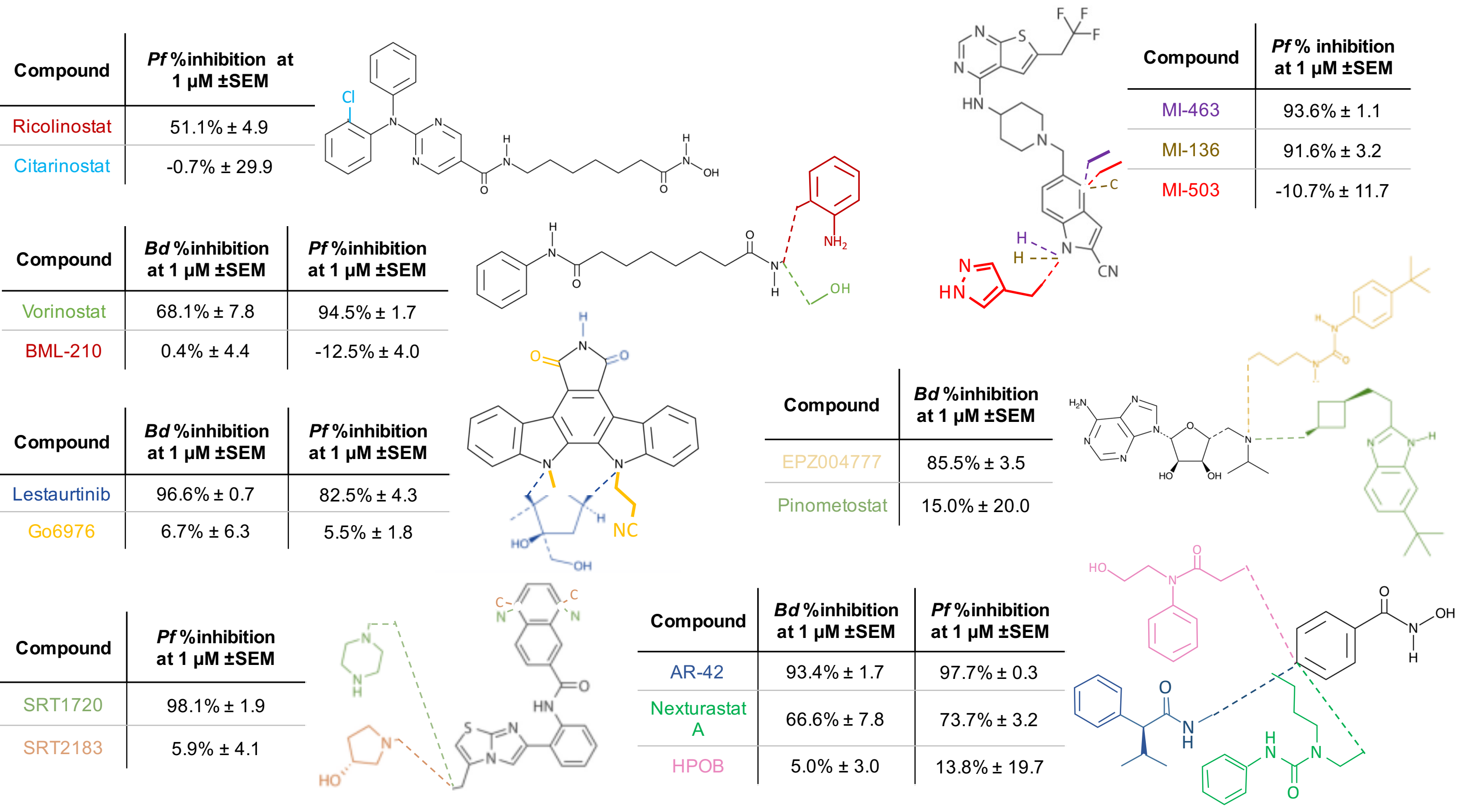

Figure S4. Structural representation of the remaining activity cliff pairs that are displayed in figure $4 \mathrm{~A}$. 

Table S1. EC50 Activity of epigenetic inhibitors tested grouped by target category. Percentage of active compounds is indicated in brackets $(n=2-3)$.

\begin{tabular}{|c|c|c|c|c|c|}
\hline \multirow[b]{2}{*}{ Target Class } & \multirow[b]{2}{*}{ Compounds } & \multicolumn{2}{|c|}{$>50 \%$ inhibition at $10 \mu \mathrm{M}$} & \multicolumn{2}{|c|}{$>50 \%$ inhibition at $1 \mu \mathrm{M}$} \\
\hline & & B. divergens & P. falciparum & B. divergens & P. falciparum \\
\hline Histone Acetylation & 10 & $0(0 \%)$ & $1(10 \%)$ & $0(0 \%)$ & $0(0 \%)$ \\
\hline Histone Deacetylation & 85 & $34(40 \%)$ & $43(51 \%)$ & $20(24 \%)$ & $25(29 \%)$ \\
\hline Histone Methylation & 51 & $28(55 \%)$ & $32(63 \%)$ & $10(20 \%)$ & $11(22 \%)$ \\
\hline Histone Demethylation & 18 & $4(22 \%)$ & $9(50 \%)$ & $1(6 \%)$ & $1(6 \%)$ \\
\hline Histone Phosphorylation & 66 & $38(58 \%)$ & $41(62 \%)$ & $11(17 \%)$ & $13(20 \%)$ \\
\hline Histone PARPylation & 22 & $3(14 \%)$ & $5(23 \%)$ & $0(0 \%)$ & $0(0 \%)$ \\
\hline Histone Reader Domains & 28 & $12(43 \%)$ & $6(21 \%)$ & $0(0 \%)$ & $0(0 \%)$ \\
\hline DNA Methylation & 14 & $2(14 \%)$ & $3(21 \%)$ & $2(14 \%)$ & $1(7 \%)$ \\
\hline Other & 30 & $4(13 \%)$ & $6(20 \%)$ & $2(7 \%)$ & $3(10 \%)$ \\
\hline$\overline{\text { Total }}$ & 324 & $125(39 \%)$ & $146(45 \%)$ & $46(14 \%)$ & $54(17 \%)$ \\
\hline
\end{tabular}

Table S2. EC90 Activity of epigenetic inhibitors tested grouped by target category. Percentage of active compounds is indicated in brackets $(n=2-3)$.

\begin{tabular}{|c|c|c|c|c|c|}
\hline \multirow[b]{2}{*}{ Target Class } & \multirow[b]{2}{*}{ Compounds } & \multicolumn{2}{|c|}{$>90 \%$ inhibition at $10 \mu \mathrm{M}$} & \multicolumn{2}{|c|}{$>90 \%$ inhibition at $1 \mu \mathrm{M}$} \\
\hline & & B. divergens & P. falciparum & B. divergens & P. falciparum \\
\hline Histone Acetylation & 10 & $0(0 \%)$ & $0(0 \%)$ & $0(0 \%)$ & $0(0 \%)$ \\
\hline Histone Deacetylation & 85 & $25(29 \%)$ & $34(40 \%)$ & $7(8 \%)$ & $15(18 \%)$ \\
\hline Histone Methylation & 51 & $15(29 \%)$ & $19(37 \%)$ & $6(12 \%)$ & $9(18 \%)$ \\
\hline Histone Demethylation & 18 & $4(22 \%)$ & $4(22 \%)$ & $0(0 \%)$ & $1(6 \%)$ \\
\hline Histone Phosphorylation & 66 & $25(38 \%)$ & $25(38 \%)$ & $2(3 \%)$ & $5(8 \%)$ \\
\hline Histone PARPylation & 22 & $1(5 \%)$ & $4(18 \%)$ & $0(0 \%)$ & $0(0 \%)$ \\
\hline Histone Reader Domains & 28 & $1(4 \%)$ & $1(4 \%)$ & $0(0 \%)$ & $0(0 \%)$ \\
\hline DNA Methylation & 14 & $1(7 \%)$ & $1(7 \%)$ & $1(7 \%)$ & $1(7 \%)$ \\
\hline Other & 30 & $3(10 \%)$ & $4(13 \%)$ & $1(3 \%)$ & $1(3 \%)$ \\
\hline$\overline{\text { Total }}$ & 324 & $75(23 \%)$ & $92(28 \%)$ & $17(5 \%)$ & $32(10 \%)$ \\
\hline
\end{tabular}

